\title{
AS CONTRIBUIÇÕES DO PIBID PARA A CONSTRUÇÃO DOS CONHECIMENTOS DIDÁTICOS DO CONTEÚDO DA GEOGRAFIA
}

\author{
The contributions of PIBID for construction of the didactic knowledge of the content of the \\ geography \\ Michael Wellington Sene* \\ Marquiana de Freitas Vilas Boas Gomes ** \\ * Doutorando em Geografia - UNICENTRO - michael mws03@hotmail.com. \\ ** Professora do PPG em Geografia - UNICENTRO - marquiana@gmail.com.
}

Recebido em 08/08/2018. Aceito para publicação em 20/08/2018.

Versão online publicada em 03/09/2018 (http://seer.ufrgs.br/paraonde)

\begin{abstract}
Resumo:
Neste artigo trazemos a discussão acerca dos conhecimentos didáticos do conteúdo de Geografia, considerados como essenciais no processo da profissionalidade docente. Neste sentido, destacamos como o Programa Institucional de Bolsas de Iniciação à Docência (PIBID) contribui na construção desse conhecimento nos acadêmicos participantes do programa, no estado do Paraná. Para identificar a construção desse conhecimento, combinou-se entrevistas, questionários, análise documental e observação participante, por meio da abordagem qualitativa, conforme Lüdke, André (1986). Os resultados apontam que o PIBID contribui significativamente para o aprofundamento dos CDC de Geografia, a medida em que proporciona espaço e condições para a criação de materiais e métodos diferenciados.
\end{abstract}

Palavras-Chave: Formação inicial de Professores; conhecimentos profissionais; profissionalidade docente

\begin{abstract}
In this article we bring the discussion about didactic knowledge of Geography content, considered as essential in the process of the teaching profession. In this sense, we highlight how the Initiation in Teaching Scholarships Institutional Program (PIBID) contributes to the construction of this knowledge in the students participating in the program, in the state of Paraná. To identify the construction of this knowledge, interviews, questionnaires, documentary analysis and participant observation were combined through the qualitative approach, according to Lüdke, André (1986). The results indicate that the PIBID contributes significantly to the deepening of the CDC of Geography, the extent to which it provides space and conditions for the creation of differentiated materials and methods.
\end{abstract}

Keywords: Initial Teacher Training; Professional knowledge; Teacher professionalism

\section{Introdução}

Neste trabalho trazemos a discussão acerca dos Conhecimentos Didáticos do Conteúdo de Geografia, considerados como essenciais no processo da profissionalidade docente. E, neste sentido, destacamos de que forma o Programa Institucional de Bolsas de Iniciação à Docência (PIBID) contribui na construção desses conhecimentos nos acadêmicos participantes do programa na área da Geografia, no estado do Paraná. 
Para García (1999) os saberes docentes devem integrar os conhecimentos de conteúdo, didático do conteúdo, pedagógico e de contexto, pré-requisitos ao processo de ensino e aprendizagem. Logo, a ausência de qualquer um dos conhecimentos citados, comprometeria a prática profissional docente.

Para o autor, o conhecimento pedagógico é aquele relacionado ao processo de ensino-aprendizado dos alunos, considerando entre outras coisas, o planejamento curricular e do ensino, legislação educacional e avaliação; 0 conhecimento de conteúdo se refere àqueles conteúdos próprios de cada ciência, os conceitos e temas, peças-chave na compreensão do objeto em estudo, afinal não se pode ensinar algo sem conhecê-lo profundamente.

O conhecimento didático do conteúdo seria, portanto, a junção do conhecimento pedagógico e do conteúdo, ou seja, de que maneira se trabalharia o conteúdo para que houvesse melhor compreensão por parte dos alunos; e o conhecimento do contexto, imprescindível para entendimento do objeto na sua relação com a sociedade historicamente determinada, da qual faz parte. Refere-se ao conhecer e compreender o local e o momento histórico no qual se insere o público (discentes) com o qual o profissional atuará.

Neste contexto, entendemos que Conhecimento Didático do Conteúdo (CDC) é o caminho utilizado pelo professor, para que o conteúdo que ensina seja melhor compreendido pelos alunos. Com isso, surgem inúmeras possibilidades e instrumentos. Shulman (2005), afirma que o CDC é possuidor de um valor particular, porque identifica os corpos de conhecimentos distintivos para o ensino. É essa categoria que permite, com maior probabilidade, distinguir o conhecimento do especialista da matéria do pedagogo. Para Lopes e Pontuschka (2011), o CDC, "tem despertado o interesse de diversos pesquisadores no mundo todo, de maneira especial pela potencialidade dessa categoria para a análise dos processos de formação inicial e continuada de professores nas diversas áreas do conhecimento" (LOPES E PONTUSCHKA, 2011, p. 93).

O CDC, para Schulman (2005, p.11): “[...] representa la mezcla entre materia y didáctica por la que se llega a una comprensión de cómo determinados temas e problemas se organizan, se representan y se adaptan a los diversos intereses y capacidades de los alumnos, y se exponen para su enseñanza".

A partir disso, na Geografia, temos diversos instrumentos didáticos e/ou metodologias, elaboradas e/ou utilizadas pelos professores na sua prática pedagógica, que permitem fazer com que os conteúdos geográficos tornem-se menos abstratos, como o trabalho de campo, os experimentos, as linguagens (gráficos, croquis, mapas mentais, fotografias) assim como recursos didáticos (mostruário de rochas, filmes, jogos, etc.), entre outros.

Para identificar a construção desse conhecimento, utilizamos a pesquisa qualitativa, conforme Lüdke e André (1986), onde combinou-se entrevistas (GIL, 1999) com 6 coordenadores de área do PIBID; questionários (MARCONI E LAKATOS, 2003), aplicados aos pibidianos durante o I Encontro Paranaense do PIBID Geografia (IPPG); análise documental (BARDIN, 2011; GODOY, 1995a) das publicações(resumos e trabalhos completos publicados na área de Geografia) nos eventos científicos do PIBID do Paraná, a saber: I Seminário do PIBID do Paraná (ISPP) II Seminário do PIBID do Paraná (IISPP)e Encontro Paranaense do PIBID Geografia( IEPPG) e, observação participante (GODOY, 1995b) de um projeto PIBID na Universidade Estadual do Centro-Oeste, UNICENTRO, durante o período de 2014 e 2015.

Os resultados apontam que o PIBID contribui significativamente para o aprofundamento dos CDC, a medida em que proporciona espaço e condições para a criação de materiais e métodos diferenciados para o ensino de Geografia, a exemplo dos jogos e trabalho de campo. Também contribui para despertar e potencializar outras habilidades necessárias aos professores para a construção dos conteúdos geográficos.

\section{Resultados e discussões}


O CDC tem despertado o interesse de diversos pesquisadores no mundo todo, de maneira especial pela potencialidade dessa categoria para a análise dos processos de formação inicial e continuada de professores nas diversas áreas do conhecimento (LOPES E PONTUSCHKA, 2011, p. 93).

$\mathrm{Na}$ Geografia, existem diversos instrumentos didáticos e/ou metodologias, elaboradas e/ou utilizadas pelos professores na sua prática pedagógica, que permitem fazer com que os conteúdos geográficos tornem-se menos abstratos, como o trabalho de campo, os experimentos, as linguagens (gráficos, croquis, mapas mentais, fotografias) assim como recursos didáticos (mostruário de rochas, filmes, jogos, etc.), entre outros. E essas diferentes possibilidades didático-pedagógicas estão inseridas nos projetos do PIBID das IES paranaenses.

Neste contexto, temos como um dos pontos norteadores do PIBID, a construção de materiais didático-pedagógicos que auxiliem a compreensão dos conteúdos. Para isso é necessário que o Conhecimento Didático e o Conhecimento do Conteúdo estejam associados.

No Estado do Paraná, a partir de nossa análise, é possível afirmar que os projetos do PIBID Geografia, buscam desenvolver esse tipo de conhecimento, desenvolvendo estratégias inovadoras para superar as dificuldades do processo de ensino-aprendizagem dos conteúdos geográficos. As socializações dos resultados nos eventos por nós investigados, comprovam a preocupação com a construção de instrumentos didáticos que auxiliem o professor na sua tarefa de construir os conhecimentos geográficos com os alunos. Nos gráficos 1, 2 e 3, elaborados a partir das publicações, é possível verificar que essa discussão permeia os projetos.

\section{Gráfico 1 - Conhecimentos Didáticos do Conteúdo por IES no ISPP, 2012}

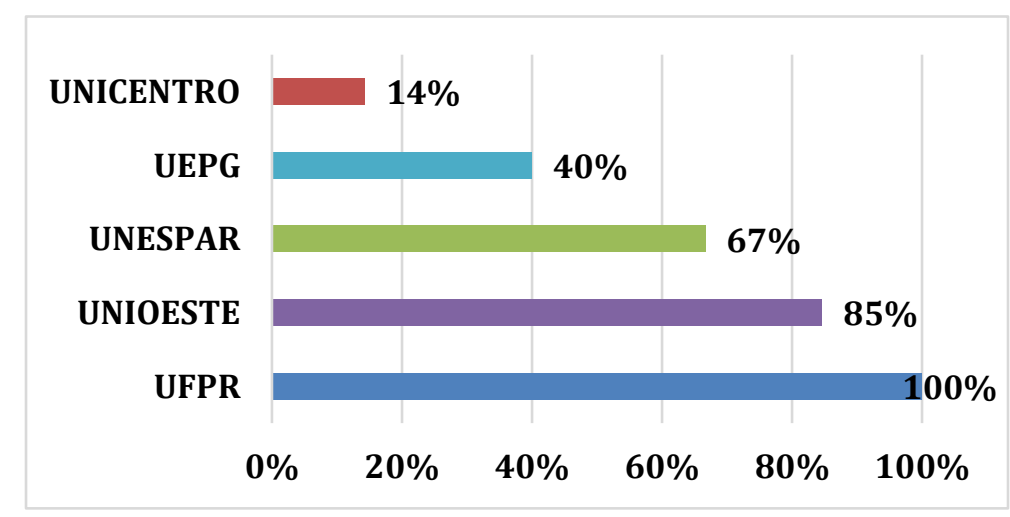

Fonte: Anais do evento

Org.: Autores. (2016).

No primeiro evento (ISPP - 2012) se destacam a UNIOESTE e a UFPR, que priorizaram em 85\% e $100 \%$, respectivamente, em suas publicações o Conhecimento Didático do Conteúdo, ou seja, existiam elementos/recursos que facilitavam o processo de aprendizagem de um conteúdo geográfico. A UNICENTRO aparece como a que menos priorizou esse conhecimento.

No segundo evento (IISPP-2014), é possível verificar que a UFPR manteve-se no mesmo patamar de $100 \%$. A UEL aparecendo pela primeira vez com publicações e também 100\% de publicações contendo o Conhecimento da Didática do Conteúdo. A UNICENTRO, ainda que aumentasse seu percentual em relação ao primeiro evento se manteve na mesma posição. 0 destaque vem para a UNIOESTE que sofreu uma queda significativa (-42\%) se comparado com o evento anterior. 


\section{Gráfico 2 - Conhecimentos Didáticos do Conteúdo por IES no IISPP, 2014}

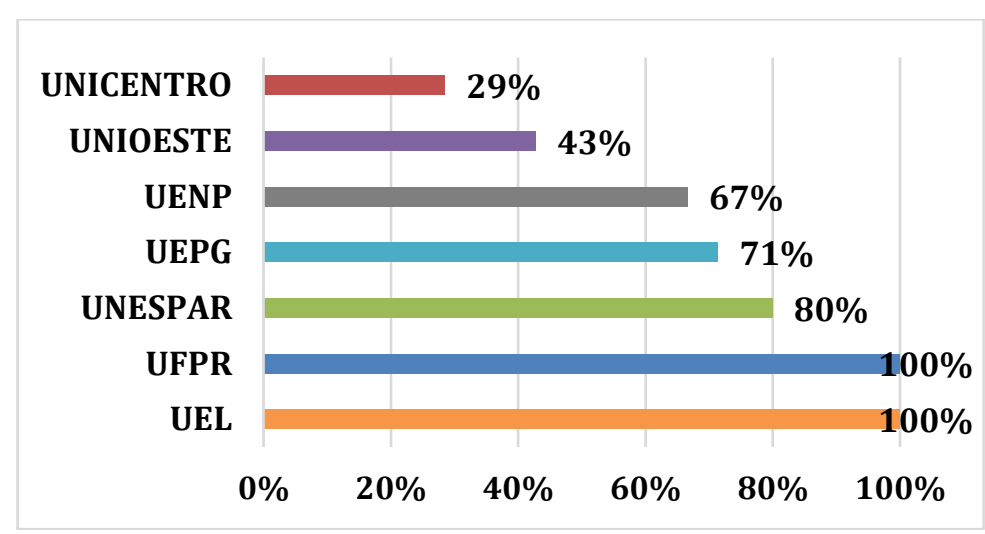

Fonte: Anais do evento.

Org.: Autores. (2016).

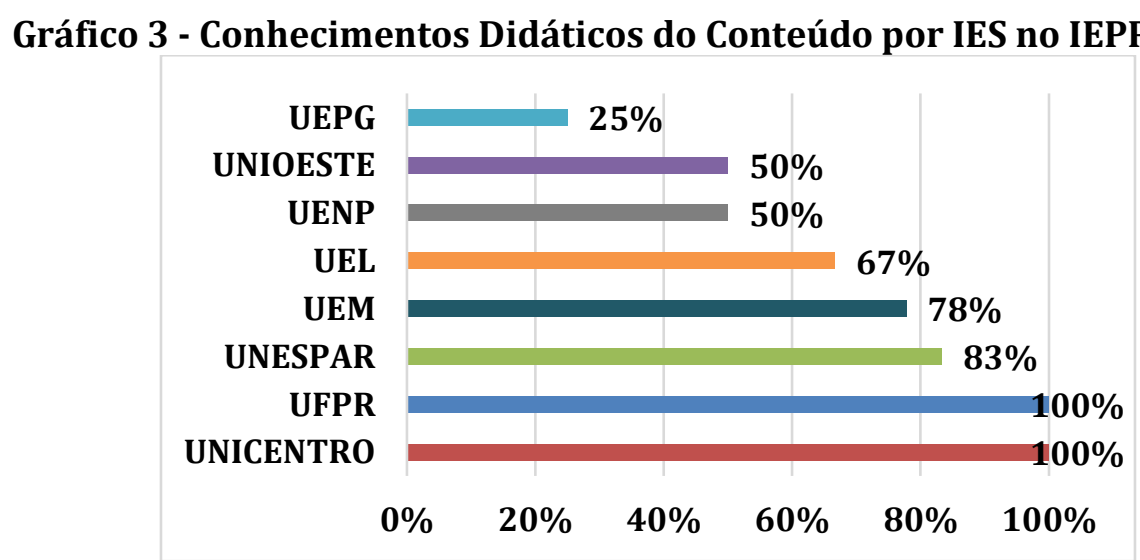

Fonte: Anais do evento.

Org.: Autores. (2016).

No terceiro evento, a UFPR manteve-se constante e novamente apareceu com $100 \%$ das publicações com Conhecimento Didático do Conteúdo. A UNICENTRO ganha destaque, também apresentando $100 \%$ de publicações relacionadas ao Conhecimento Didático, um aumento significativo $(+71 \%)$ se compararmos os três eventos.

A partir desses resultados, percebemos a preocupação dos projetos em desenvolver instrumentos que possibilitem melhor compreensão dos conteúdos geográficos. Os mais frequentes foram: trabalho de campo, jogos de tabuleiro, caça ao tesouro, trilha, charges, maquetes, TIC's, fotos, vídeos, mostruários de rochas, filmes, além das estratégias mais convencionais, como as aulas expositivas e/ou expositivas dialogadas.

A partir das publicações encontramos inúmeros exemplos desses instrumentos didáticos, a publicação C64 apresenta uma série deles:

Jogo de tabuleiro - foi elaborado para reforçar os conteúdos sobre as regiões do Brasil. Após uma aula explicativa sobre o conteúdo os alunos se dividiram em grupos de cinco a seis jogadores. Cada jogador era representado por uma peça de cores distintas. Um dos participantes do grupo retirava uma carta aleatória e perguntava sobre as regiões do Brasil para o jogador que ganhou na soma da pontuação dos dados. Em cada acerto avançava-se 
uma casa do tabuleiro.

Jogo das eras geológicas - Para complementar o conteúdo a respeito das eras geológicas foi desenvolvido um bingo sobre o assunto. 0 bingo foi confeccionado com questões enumeradas de acordo com o conteúdo e com o número correspondente a resposta correta na cartela.

Jogo da Memória - Ao trabalhar com o conteúdo sobre a divisão política do Brasil, surgiu a necessidade de realizar uma revisão para avaliação bimestral. Sendo assim, foi feito este jogo com o objetivo de memorização dos estados e capitais do Brasil. Construiu-se 17 jogos contendo 44 peças cada, para que os alunos jogassem em duplas.

Jogo Show da Geografia - é uma simulação da versão original "show do milhão". Foi elaborado em PowerPoint, sendo um jogo de perguntas e respostas. As perguntas foram baseadas na aula sobre a importância da vida humana no planeta e foi complementada com o vídeo Life after people - ("O mundo sem ninguém"). Após a aula expositiva os alunos foram orientados a irem ao salão de convivência em que assistiram o vídeo. Ao termino do vídeo os alunos foram dividos em dois grandes grupos de cinquenta crianças, sendo selecionados representantes de cada grupo para responder a pergunta que aparecia na tela. A cada pergunta respondida corretamente os pontos eram acumulados. Ao final, a equipe vencedora ganhou um baú com barras de chocolates, simulando as barras de ouro do jogo original. (Publicação C64, IEPPG, 2015).

Ainda sobre esses instrumentos temos a publicação A29:

Considerando que a construção do conhecimento dentro da sala de aula exige que o professor proporcione aos seus alunos novos modos de aprendizagem, se fazem necessários métodos que busquem um envolvimento real entre alunos e professores durante a prática pedagógica, propiciando uma maior interação entre as partes nas atividades [...] Sendo assim, este trabalho tem como objetivo demonstrar a relevância em pensar o ensino de Geografia que possibilite ao aluno uma maior interação com o conteúdo que será trabalhado, mediante o uso de modelos de fósseis e maquetes, para o tratamento de conteúdos escolares ligados ao conceito de paisagem [...] (Publicação A29, ISPP, 2012).

Como em qualquer prática pedagógica a utilização de recursos como fotos, filmes, charges, jogos e dinâmicas é importantíssima, pois mobiliza o aluno em situações de reflexão e de participação ativa, individual ou em grupo. Na Geografia ganha destaque neste contexto do Conhecimento Didático do Conteúdo, o trabalho de campo.

0 trabalho de campo é de fundamental importância para que o aluno compreenda as relações entre a teoria e prática. A teoria visa construir um embasamento conceitual e metodológico previamente, e a prática de campo, permite a sua reelaboração e compreensão por meio de uma situação concreta. Como exemplo da utilização de trabalho de campo no ensino de geografia, temos a publicação C34:

[...] Em seguida, realizou-se um pequeno trabalho de campo na quadra da referida escola, com o objetivo de os alunos aprenderem a utilizar e manusear a bússola, encontrando os pontos de referências naturais (no caso, o Leste e o Oeste, onde o sol nasce e se põe), e ensinando-os a encontrarem os pontos cardeais e colaterais, para que, deste modo, se sentissem seguros e prontos para realizar o campo. Esta primeira atividade de campo permitiu também a observação da paisagem do entorno da escola e, assim, a determinação dos referenciais utilizados na confecção do croqui. Os materiais utilizados para o desenvolvimento da atividade foram: bússolas juntamente como materiais de papelaria para confecção do croqui - onde foram impressos -. Os alunos, por sua vez, foram orientados a utilizarem para anotações, cadernos, lápis ou canetas. (Publicação C34, IEPPG, 2015). 
Os próprios bolsistas em seus trabalhos mostram a importância do trabalho de campo para o Ensino de Geografia, conforme vemos na publicação C36:

[...] o trabalho de campo é uma ferramenta que pode e deve ser utilizado pelo docente para auxiliar a construção do saber geográfico do aluno. Através do exercício prático o aluno comprova o que foi mencionado na teoria, ou seja, fixa o conteúdo trabalhado em sala de aula e adquire experiência e base teórica para aulas futuras. Com a junção da teoria e da prática, o professor elimina a possibilidade de aulas apenas expositivas e eleva seu nível de mediação no processo de ensino-aprendizagem. Muitos professores ainda mantêm certo receio em realizar trabalhos fora da classe apontando, coerentemente, inúmeros empecilhos em sua realização. Entretanto, a experiência mostra que a realização dos trabalhos de campo é um fator importante na tarefa de "conquista" dos alunos para o estudo da Geografia e um momento especial de fortalecimento de sua identidade no currículo escolar. Este trabalho representa um esforço nessa direção (Publicação C36, IEPPG, 2015).

A questão da construção dos Conhecimentos Didáticos do Conteúdo, por meio do planejamento e a construção de materiais didáticos, foi destacada também na enquete aplicada aos pibidianos como uma contribuição do programa para o processo de formação inicial destes. Também no estudo realizado pela Fundação Carlos Chagas (2014), uma das principais contribuições para os pibidianos em nível nacional e que também apareceu no caso paranaense é que o PIBID: "Estimula a iniciativa e a criatividade, incentivando os licenciandos a buscar soluções, planejar e desenvolver atividades de ensino e a construir diferentes materiais didáticos e pedagógicos" (p.104).

O objetivo maior para que esses materiais sejam criados, é certamente a dinamização do ensino através de práticas diferenciadas daquelas que o professor regente utiliza no dia-a-dia, que faz com o que as intervenções do PIBID nas escolas sejam bem recebidas/aceitas pelos alunos.

Os pesquisadores que estudam o tema como Biason (2013), Anjos et al (2014), tem afirmado que o PIBID traz contribuições significativas para o processo de formação inicial. Na visão dos pibidianos paranaenses, temos várias contribuições do PIBID para a formação inicial docente (Quadro 1).

Quadro 1 - Contribuições do PIBID para a formação inicial docente

\begin{tabular}{|c|c|}
\hline Possibilidades do PIBID para a Formação Inicial & Percentual do Total \\
\hline $\begin{array}{c}\text { Crescimento/experiência profissional e prática } \\
\text { docente }\end{array}$ & $61 \%$ \\
\hline Profissionalidade docente & $11 \%$ \\
\hline Acréscimo ou ajuda nos conteúdos da Graduação & $10 \%$ \\
\hline Alternativa para experiência extra estágio & $7 \%$ \\
\hline Desenvolvimento de recursos didáticos & $7 \%$ \\
\hline Não respondeu & $4 \%$ \\
\hline
\end{tabular}

Fonte: Questionários aplicados aos pibidianos durante o IEPPG, 2015.

Org.: SENE, M. W., (2016).

Os dados da pesquisa, não fugiram da regra e das considerações dos autores já mencionados. Apenas, reforça-os. Parece óbvio afirmar que o PIBID enquanto política pública tem contribuído significativamente para a formação inicial do professorado brasileiro, porém, vale destacar que por ser um programa bastante recente (a partir de 2007 para algumas áreas e para as universidades federais; e 2010 para as demais áreas e IES) é difícil encontrar referências para comprovar isso. Logo, os dados 
aqui apresentados mostram-se importantes no sentido de dar visibilidade aos benefícios suscitados pelo programa.

Neste sentido, poder afirmar que para 61\% dos respondentes, o PIBID tem contribuído para um crescimento profissional e para a prática docente, aliado aos dados anteriormente apresentados, mostra que a política tem dado certo. Abaixo apresentaremos alguns dos depoimentos dos respondentes $(\mathrm{R})$ :

Em muitos sentidos, como ser humano, como docente aliando teoria e prática. Além disso, o PIBID acrescentou muito em meu currículo por escrever artigos e participar de eventos e, nestes eventos podemos compreender o quanto é importante esse programa para a vida discente (R14).

Fez com que eu realmente me encontrasse no curso, descobrindo o que realmente quero para o meu futuro, minha formação teve como peça fundamental o PIBID, que me ensinou além da teoria, me proporcionando a passar por todos os desafios que vou encontrar na escola (R29).

O programa em âmbito didático contribuiu de modo significativo no ensino de Geografia, nas referências e conhecimentos metodológicos, vivências e experiências na minha formação, dando suporte na formação em licenciatura (R41).

Com relação à construção da profissionalidade docente a partir do PIBID, que é entendida como aqueles saberes, comportamentos, valores, atitudes, construção de conhecimentos que são específicos da profissão docente, o reconhecer-se professor, foi apontado por $11 \%$ dos respondentes.

Morgado (2011) compreende que: "[...] o saber profissional do professor não possa restringir-se ao mero domínio de um conjunto de conhecimentos científicos relativos aos conteúdos curriculares ou de um conjunto de conhecimentos científicos e metodológicos das ciências da educação" (p. 797). Logo, os conhecimentos práticos e metodológicos são imprescindíveis para a construção da profissionalidade docente. Aliados aos conhecimentos científicos adquiridos na universidade, os conhecimentos práticos proporcionados pelas intervenções do PIBID trazem para os pibidianos uma contribuição mais significativa no processo de profissionalidade docente. Podemos observar isso, a partir da fala de um respondente: "Na oratória, conseguir sistematizar o pensamento para conseguir expressar em frente a uma plateia, como preparar uma aula, a questão do plano de aula e formas didáticas de trabalhar os conteúdos geográficos" (R4).

Em muitos questionários analisados, é possível identificar que o PIBID, além de proporcionar uma melhor formação profissional, auxilia no desenvolvimento acadêmico, no sentido de aperfeiçoamento nas apresentações de trabalhos, seminários, redação de artigos e resenhas, entre outros.

Também uma ajuda significativa nos conteúdos vistos na graduação, no qual precisam revisitá-los e criar uma metodologia que dê conta de ser compreendida pelos alunos nas escolas no momento da intervenção do PIBID, a conhecida transposição didática. No entanto, o que vale destacar é esse aprofundamento teórico-conceitual, seja através dos momentos de preparação de materiais didáticos e oficinas, seja nas reuniões com os coordenadores de área, que conforme registrado nas entrevistas, são realizadas semanal ou quinzenalmente.

\section{Considerações Finais}

A formação do professor compreende diferentes relações, entre elas professor-aluno, professorprofessor, professor-comunidade escolar, professor-conteúdo a ser ensinado, domínio de diferentes metodologias e tecnologias ao processo ensino-aprendizagem, conhecimentos pedagógicos entre 
outros, que compõem as dimensões necessárias a pratica profissional docente. Algumas dessas dimensões são aprimoradas com a participação dos professores em formação inicial, através do PIBID.

O PIBID enquanto política pública tem contribuído significativamente para a formação inicial de professores no Brasil, principalmente no que se refere à formação inicial de professores com atividades em sala de aula, com os alunos, no convívio com a escola, demais professores, equipe pedagógica, direção, comunidade escolar. Tudo isso faz com que a formação inicial seja potencializada, por permitir o contato direto com o futuro local de trabalho, desde o início da formação, auxiliando no processo de construção da profissionalidade docente de cada participante. Daí a importância da manutenção de programas como este.

Como pudemos perceber, no Paraná, é possível notar que o PIBID Geografia tem contribuído para a construção dos conhecimentos elementares para a formação de professores, especialmente na construção dos Conhecimentos Didáticos de Conteúdo, a medida em que proporciona espaço e condições para a criação de materiais e métodos diferenciados para o ensino de Geografia, a exemplo dos jogos e trabalho de campo.

O programa também contribui para despertar e potencializar as habilidades, como oratória, escrita, sistematização e análise de dados, entre outras, que são necessárias aos professores para a construção dos conteúdos geográficos. E essas diferentes possibilidades didático-pedagógicas estão inseridas nos projetos do PIBID das IES paranaenses.

\section{Referências}

ANJOS, T. R., PEREIRA, L. R., ORLANDINI, P., OZELO, H. F. B. Contribuições do PIBID na formação de professores: uma reflexão continuada. Polyphonía, v. 25/1, jan./ jun. 2014. p. 131 - 143.

BARDIN, L. Análise de Conteúdo. Tradução: Luis Antero Reto Augusto Pinheiro, São Paulo: Edições 70, 2011.

BIASON, A. H. Formação Inicial de professores da educação básica: PIBID relacionando teoria à prática. In: XI Congresso Nacional de Educação - Educere, Curitiba. Anais... Curitiba, p.14432 - 14461, 2013.

FUNDAÇÃO CARLOS CHAGAS Um estudo avaliativo do Programa Institucional de Bolsa de Iniciação à Docência (PIBID). São Paulo: FCC/SEP, 2014.

GARCIA, C. M. Formação de professores: para uma mudança educativa. Trad. Isabel Narciso. Porto: Porto Editora. 1999.

GIL. A. C. Métodos e técnicas de pesquisa social. 5. ed. São Paulo: Atlas, 1999.

GODOY, A. S. Introdução à pesquisa qualitativa e suas possibilidades. Revista de Administração de Empresas. Vol. 35, n.2 p. 57-63, 1995a.

Pesquisa Qualitativa: tipos fundamentais. Revista de Administração de Empresas. Vol. 35, n.2 p. 20-29, 1995b.

LOPES; C. S.; PONTUSCHKA, N. N. Mobilização e construção de saberes na prática pedagógica do professor de Geografia. Geosaberes, Fortaleza v. 2, n.3, p. 88-104, 2011.

LUDKE, M. e ANDRÉ, M. E. D. A. Pesquisa em educação: abordagens qualitativas. São Paulo: EPU, 1986.

MARCONI, M. de A.; LAKATOS, E. M. Fundamentos de metodologia científica. 5. ed. São Paulo: Atlas, 2003.

SHULMAN, L. S. Conocimiento y enseñanza: fundamentos de la nueva reforma. Professorado. Revista de Currículum y Formación del professorado. Granada - España, ano 9, n.2. p. 1 - 30. 2005. 